\title{
Identification of Extracytoplasmic Proteins in Bradyrhizobium japonicum Using Phage Display
}

\author{
Anna Rosander, ${ }^{1}$ Lars Frykberg, ${ }^{1}$ Nora Ausmees, ${ }^{1}$ and Peter Müller ${ }^{2}$ \\ ${ }^{1}$ SLU, Department of Microbiology, P.O. Box 7025, SE-750 07 Uppsala, Sweden; ${ }^{2}$ Philipps University Marburg, Cell \\ Biology and Applied Botany, Karl-von-Frisch-Str. 8, D-35032 Marburg, Germany
}

Submitted 23 September 2002. Accepted 4 April 2003.

A novel gene bank of Bradyrhizobium japonicum USDA110spc4 was constructed using pG3DSS, a phagemid vector designed for detecting genes encoding secreted proteins. In this phagemid, the phage protein III lacks its indigenous signal peptide required for protein secretion, thus recombinant fusion proteins are displayed on the phage surface only if a functional signal peptide is provided by an inserted DNA fragment. In addition, the $\mathrm{N}$-terminal half of protein III has been replaced by a short linker region (the E-tag) that is recognized by a monoclonal antibody, which enables isolation of phages displaying a fusion protein. The expression library described here, therefore, provides a powerful means to affinity select for B. japonicum genes encoding extracytoplasmic proteins. In total, 182 DNA sequences were analyzed, among which 132 different putative extracytoplasmic proteins could be identified. The function of most proteins could be predicted and support an extracytoplasmic localization. In addition, genes encoding novel extracytoplasmic proteins were found. In particular, a novel family of small proteins has been identified that is characterized by a conserved pattern of four cysteine residues.

Bacteria are usually unicellular microorganisms, but nevertheless, the cells are well organized in several compartments where different simultaneous biochemical processes require specific reaction conditions. All proteins are synthesized in the cytoplasm, but a considerable number are translocated across the cytoplasmic membrane. According to Pugsley (1993) and Tjalsma and associates (2000), the proportion of extracytoplasmic proteins has been estimated to be 20 to $25 \%$. They are involved in many diverse and essential cell functions, such as respiration, nutrient uptake and osmoregulation, motility and sensing of stimuli within the environment, macromolecular transport and protein assembly, cell wall turnover, and signal transduction. As reported recently by Stuart and Neupert (2000), protein translocation across the cytoplasmic membrane of gram-negative bacteria is mediated by at least four distinct pathways: the general secretory $(\mathrm{Sec})$ pathway (Danese and Silhavy 1998), the signal recognition particle (SRP)-dependent pathway (Meyer et al. 1982), the twin-arginine translocation (Tat) system (Berks 1996), and the more recently discovered YidC-dependent process (Samuelson et al. 2000).

In bacteria interacting with plants or animals, many exported proteins are enzymes, adhesions, or toxins, which may be important virulence determinants. In interactions between plantpathogenic or symbiotic bacteria and their host, bacterial

Corresponding author: P. Müller; E-mail: muellerp@ @staff.uni-marburg.de. secreted proteins like hemicellulases, pectinases, and cellulases are known to degrade the plant cell walls and are a prerequisite of bacterial infection. Members of the gram-negative family Rhizobiaceae are known to interact with legume plants and to induce the formation of novel root organs called root nodules. Plant cell wall degrading enzymes have been suggested to be involved in root hair deformation, infection thread formation, and bacterial release into the central nodule cells (Fahraeus and Ljunggren 1959; Hubbell et al. 1978; Ljunggren and Fahraeus 1961). The rhizobial periplasmic proteins, outer membrane proteins, and secreted proteins have been estimated to constitute as much as $36 \%$ of the total amount of proteins (Lugtenberg 1998). Among the 6,667 proteins encoded by the Sinorhizobium meliloti genome (Galibert et al. 2001), about $10 \%$ have been calculated to have N-terminal signal peptides. Recently, the genome sequence of Bradyrhizobium japonicum strain USDA110 has been released by the Kazusa Institute (Kisarazu, Japan). The B. japonicum genome size is $9.1 \mathrm{Mb}$, and 8,317 potential proteins were described. (Kaneko et al 2002). Among 1,479 proteins randomly chosen from the $8,317 \mathrm{~B}$. japonicum open reading frames (ORFs), at least $9 \%$ were found to have an $\mathrm{N}$ terminal signal peptide (P. Müller, unpublished data).

The classical N-terminal signal peptide consists of three domains, an amino terminal $(\mathrm{N}-)$ region with one or several positively charged amino acids, a central hydrophobic (H-) region, and a more polar carboxy-terminal (C-) region. The signal peptidase I (SpaseI) favors small, uncharged residues in positions -3 and -1 relative to the cleavage site (Perlman and Halvorson 1983; von Heijne 1983). Therefore, SPaseI signal peptide prediction is based on a conserved structural pattern rather than on conserved amino acid sequences. In $B$. japonicum, two functional signal peptidases have been found by transposon TnphoA mutagenesis (Bairl and Müller 1998; Müller et al. 1995a). A third signal peptidase gene has been predicted by the genome sequence of B. japonicum (Kaneko et al 2002), but it has not yet been proven to be functional. Unlike in Escherichia coli, where mutations in the single lep gene encoding a universal leader peptidase are lethal, $B$. japonicum sipS or sipF mutants are viable. The observation that these bacterial mutations in combination with soybean result in different symbiotic phenotypes (Müller et al. 1995b) is intriguing and has led to the concept that both signal peptidases can functionally substitute for each other under freeliving conditions but that each of them plays specific roles in the process of bacteroid differentiation, function, and maintenance. Therefore, we intended to develop and apply an efficient means to identify and analyze $B$. japonicum precursor proteins.

The most frequently used strategy to identify extracytoplasmic proteins has been to construct fusion proteins with 
export-specific reporter proteins, such as alkaline phosphatase (PhoA) (Manoil et al. 1990) and TEM $\beta$-lactamase (BlaM) (Broome-Smith et al. 1990) of E. coli. In addition, we have recently shown that phage display can be used to identify genes encoding signal peptides (Rosander et al. 2002). Phage display is usually used for identification of proteins and peptides with affinity for other molecules. Generally, systems based on the bacteriophage M13 are used for this purpose (Smith and Petrenko 1997). The phage particle is continuously assembled in and extruded from the bacterial membranes (Russel et al. 1997). The minor phage coat protein (protein III) is directed to the inner membrane by its signal peptide. This unusual way of assembly can be used for selection of peptides mediating translocation into the membrane. A display library made in a phagemid vector lacking the signal peptide for protein III is an easy and efficient way to select for genes encoding signal peptides. In this paper, we apply this novel display method on the genome of B. japonicum and show that it can be used for a high-throughput analysis of signal-peptide dependent secretion.

\section{RESULTS}

The $B$. japonicum signal peptide phage display library.

Randomly fragmented chromosomal DNA from B. japonicum USDA110spc4 was ligated into the SnaBI site of the pG3DSS vector and was electrotransformed into E. coli TG1 cells. This procedure yielded $1 \times 10^{8}$ transformants, $95 \%$ of which carried an insert, as determined by colony polymerase chain reaction analysis, using primers G3DelRev and G3DSSfw. The transformants were infected with helper phage R408, which starts production of two types of phenotypically identical phage, with a mixture of wild-type and recombinant pIII but containing either the phage genome or the phagemid. The latter are referred to as phagemid particles. The final library had a titer of $1 \times 10^{10} \mathrm{CFU}$ (colony forming units), i.e.,
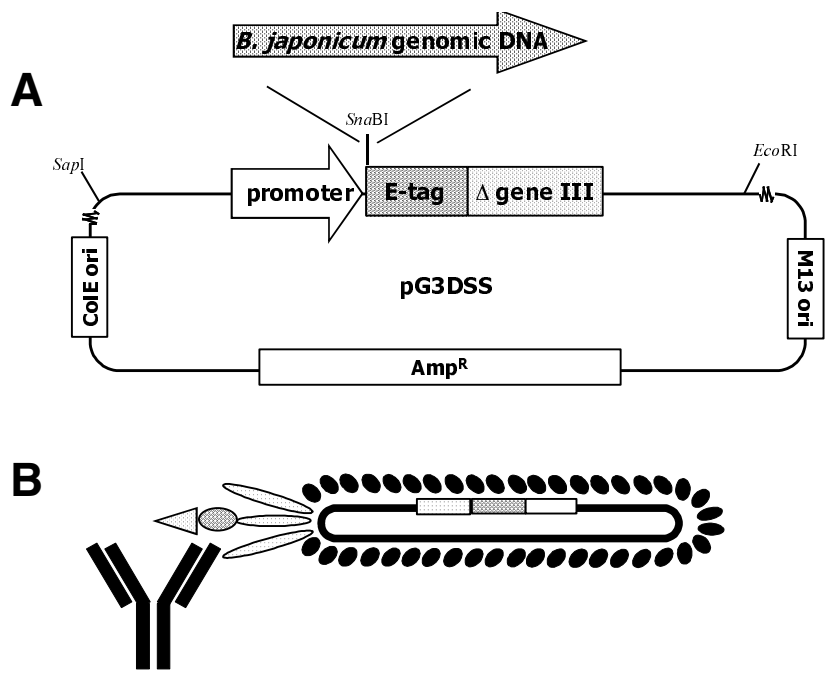

Fig. 1. A, Schematic presentation of phagemid vector pG3DSS. The unique SnaBI restriction site was used for the insertion of Bradyrhizobium japonicum DNA fragments. The promoter for expression of the insert is from the spa gene derived from Staphylococcus aureus. Plasmid not drawn to scale. B, Schematic presentation of phage display. The truncated protein III is a part of the phage coat. The E-tag linker and partial B. japonicum protein will be displayed on the phage surface in fusion with protein III, and recombinant phagemid particles can be isolated by affinity-selection against immobilized monoclonal $\alpha$-E-tag antibodies. The three different filling patterns indicate that fusion products originate from three different sources: B. japonicum, E-tag, and $\Delta$ geneIII. phagemids per ml. The average fragment size $(1 \mathrm{~kb})$ of the gene bank and the $B$. japonicum genome size of $9.1 \mathrm{Mb}$ (Kaneko et al. 2002) means that the genome has been covered $10^{4}$-fold. The gene III-based phagemid vector pG3DSS (Rosander et al. 2002) (Fig. 1A) lacks the ribosome binding site (RBS) and a signal peptide for protein III. Thus, only phagemid clones containing a DNA insert with an RBS and encoding a functional signal peptide will result in a fusion protein with the E-tag and protein III that is displayed at the phage surface. Subsequently, antibodies against the E-tag can be used to affinity-select phagemid particles containing an insert with the above features (Fig. 1B).

\section{Selection for extracytoplasmic protein fusions by phage display.}

Immobilized $\alpha$-E-tag antibodies were used for affinity selection of phagemid particles displaying recombinant protein. In a typical experiment, the number of eluted phagemid particles increased from $1.6 \times 10^{5} \mathrm{CFU} / \mathrm{ml}$ to $4.2 \times 10^{8} \mathrm{CFU} / \mathrm{ml}$, i. e., over a 1,000-fold increase from the first to the second panning, indicating that the clones expressing the E-tag are enriched. Several panning experiments were performed with reproducible results. A random selection of clones obtained in the first experiment from the first panning and the repanning were subjected to plasmid preparation and subsequent sequencing of the inserted DNA. Results from the sequencing indicated that one round of panning was sufficient to obtain about $90 \%$ correct clones (discussed below). Thus, during the remainder of the study, only clones from the first panning were randomly chosen for sequence analysis to avoid the sequencing of identical clones.

\section{Analysis of affinity selected clones.}

More than 200 clones were subjected to DNA sequencing. Of these, 182 sequences were sufficiently reliable to establish the amino acid sequences for further analyses. The sequence was analyzed using the signal $\mathrm{P}$ prediction server (Nielsen et al. 1997). In Table 1, we have chosen to include only those sequences that scored above the cutoff value in at least two of the four parameters (max C-score, max Y-score, max S-score and mean S-score). Of these, the max Y-score, and mean S-score have been reported to give the best discrimination performance (Nielsen et al. 1999). In total, 167 (92\%) deduced amino acid sequences represent known or putative extracytoplasmic proteins. Putative signal peptide sequences were detected in 165 clones, 130 unique signal peptides, and 35 clones with signal peptides contained within the group of 130 . In addition, another two putative transmembrane proteins (131 to 132) that do not hold to the definition above are included in Table 1 and comprise a separate group. In some cases, it is possible that the predicted signal peptide could be noncleavable and, thereby, should rather be referred to as signal anchors. However, it can be difficult to discriminate between the two types (Nielsen et al. 1997), and both types mediated translocation of proteins into the membrane. Therefore, in this article, they are simply referred to as signal peptides. The N-terminal parts of the putative signal peptide proteins fused to the E-tag varied in length from 21 to 388 amino acids. Of 167 clones, $37 \%$ encoded up to 70 amino acids, $32 \%$ were in the range of 71 to 140 amino acids, $19 \%$ were in the range of 141 to 210 amino acids, and $13 \%$ encoded more than 211 amino acids. Fifteen clones were regarded as background and are not included in Table 1. Eight clones contained genes in the opposite orientation, and seven clones were considered unlikely to encode extracytoplasmic proteins. Twenty-six genes were isolated more than once (shown by indices in Table 1). Of these, only two were represented by clones with identical inserts, while the rest were 
represented by two, three, four, or five clones with overlapping inserts derived from the same gene. Rhizobase ORF blr1408 is such an example; E-tag fusions were obtained at positions 21 (within the signal peptide), 32 (after position +1 ), position 122 , and position 196, which is exactly between the last amino acid and the stop codon (S125b, S118b, L111, mr023) [94]. Although the inserts in many clones encode rather short polypeptides, there are also examples of clones encoding large E-tag fusion polypeptides, such as S203 [52] and S121b [35], which encode polypeptides of 268 and 332 amino acids, respectively, prior to the E-tag oligopeptide.

In 84 cases, highly similar sequences were found in the ERGO database, most of them being sequences obtained from the closely related strain $B$. japonicum USDA 438 . Due to the transient availability of the ERGO database, not all sequences were checked for similarities. Finally, when the total B. japonicum genome became available, our sequencing data were used to identify the corresponding ORFs in the RhizoBase of the Kazusa Institute. All results were included in separate columns of Table 1. A comparison of the E-tag fusion sequences with the circular chromosomal map of the B. japonicum genome showed that the fragments were randomly distributed.

To test the efficiency by which individual clones mediate display of the E-tag, phage stocks from seven positive and five negative clones were assayed. The titer of the phage stocks was adjusted to $10^{8} \mathrm{CFU} / \mathrm{ml}$ and was affinity-selected against $\alpha$-E-tag antibodies. As seen in Table 2, phages from clones with a signal peptide bound more than 1,000 times more efficiently than negative clones with one exception, clone S131b [84]. Phages from this clone showed an intermediate bindinga much better binding than phages from negative clones, but still a lower binding than phages from the positive clones. The insert of this clone does not carry a promoter or RBS and does not encode the seven first N-terminal amino acids of the protein. However, the first part of this insert encodes a number of hydrophobic amino acids that, in the native protein, are likely to be a signal peptide and, apparently, the truncated version in combination with the vector sequence can function to some extent as a signal peptide. Therefore, this clone was included in Table 1 [84].

\section{Analysis of signal peptide sequences.}

For 130 unique clones encoding presumed or recognized extracytoplasmic proteins and when a putative signal peptide could be detected in the deduced amino acid sequence, the signal peptides were evaluated by the Signal P V1.1 algorithm and were included in Table 1. The longest predicted signal peptide sequences were found in clones S103 (59 aa) [95], S122b (56 aa) [82], and L101 (55 aa) [15]. The shortest signal peptide sequence consists of only, 13 aa (S112b [56]), although other cleavage sites are conceivable, and 17 aa (S208 [68]). The calculated average length, based on unique signal peptide sequences, was 27 aa. The positively charged amino acids lysine $(\mathrm{K})$ and arginine $(\mathrm{R})$ could be found at the N-terminal part preceding the hydrophobic core region in all putative signal peptides, with only three exceptions. Another common feature in signal peptides are helix-breaking amino acids proline $(\mathrm{P})$ and glycine $(\mathrm{G})$ in the middle of the hydrophobic domain and at position -7 to -4 relative to the predicted cleavage site. These amino acids are found at position -7 to -4 in about $65 \%$ of all signal peptides. Frequently, there is a glycine in the -5 position and a proline at the -4 position. Alanine in the -3 and -1 positions was found in $67 \%$ and $94 \%$ of all cases, respectively. Furthermore, it was noted that the most common amino acid residue following the cleavage site was glutamine $(\mathrm{Q})$ and alanine (A), which occurred in frequencies of $35 \%$ and $29 \%$, respectively. In two cases (phagemids S119 [76] and L205
[108]), the first amino acid residue of the mature protein was cysteine $(\mathrm{C})$, which is the rule in processing sites of lipoproteins (Wu 1996). These inserts are left without any functional similarity to other well-defined proteins in the databases, which is why the functional relevance of this observation is unclear. Although several signal peptides contain twin arginine residues, none of these sequences is identical to the Tat consensus motif (S/TRRxFLK) (Berks 1996). Examples are L112 ([126] SRRFFLR), L208 ([24] SRRLMLG), and mr042 ([14] TRRLVLA). Neither do their putative functions support the idea that these proteins are translocated by the Tat system.

\section{Functional classification.}

Based on sequence similarities or other features, we have divided the deduced proteins in this article into eight groups (Table 1). The groups can be summarized as follows. Thirtytwo different sequences encode putative periplasmic binding proteins of $\mathrm{ABC}$ transport systems or were found to be similar to putative (inner membrane) transporters. Six sequences were related to outer membrane proteins. A group of 28 sequences, classified as miscellaneous, is associated with different biochemical functions. In addition, 28 conserved hypothetical proteins of different origins were detected in the databases, while 11 sequences were left without any similarities. Most interestingly, no corresponding ORFs for 12 clones could be identified in RhizoBase, and no corresponding nucleotide sequences for 13 clones could be identified in the B. japonicum genomic sequence. It should be noted that there are some overlaps between the different groups, e.g., transporter proteins can also be found in the group designated "clones with inserts not found in RhizoBase."

When the deduced amino acid sequence of the insert in phagemid S148 [113] was blasted against the ERGO site, several hits were found in the partial genome of B. japonicum USDA438. When these sequences were aligned, a surprising result was obtained. The putative ORFs were in the range of only 75 to 92 amino acids, the N-termini of which were predicted to represent signal peptides, and the other parts were characterized by a conserved core region containing a pattern of four cysteine residues (data not shown). By blasting S148 against all available microbial genome sequences in the NCBI database, several similar sequences in Rhodopseudomonas palustris were found. Eleven similar sequences that exhibit the same pattern of conserved cysteine residues were later also found in B. japonicum USDA110, although only one of those putative proteins has been annotated (blr0858). These results are summarized in Figure 2. Most likely, the proteins aligned in Figure 2 form a novel protein family, designated the $4 \mathrm{C}$ family. Interestingly, six of these homologous genes in $B$. japonicum (4CBj5-4CBj6, 4CBj7-4CBj8, and $4 \mathrm{CBj} 9-4 \mathrm{CBj} 10)$ are located pair-wise next to each other on the chromosome. Likewise, two members of this family in $R$. palustris are neighbors. The lack of transmembrane domains and the small size of the mature proteins suggest that they are translocated across the pores of the outer membrane and, thus, can be assumed to be secreted proteins.

\section{DISCUSSION}

Analysis of the DNA sequences from 182 clones isolated from the B. japonicum library after affinity selection showed that about $90 \%$ indeed encoded extracytoplasmic proteins. These 167 clones contained parts of 132 different genes, while the remaining 35 clones had inserts already found among the 132. Compared with a previous study using a Staphylococcus aureus signal sequence library (Rosander et al. 2002), the number of unique genes isolated and the frequency of correct 
Table 1. List of E-tag fusion proteins

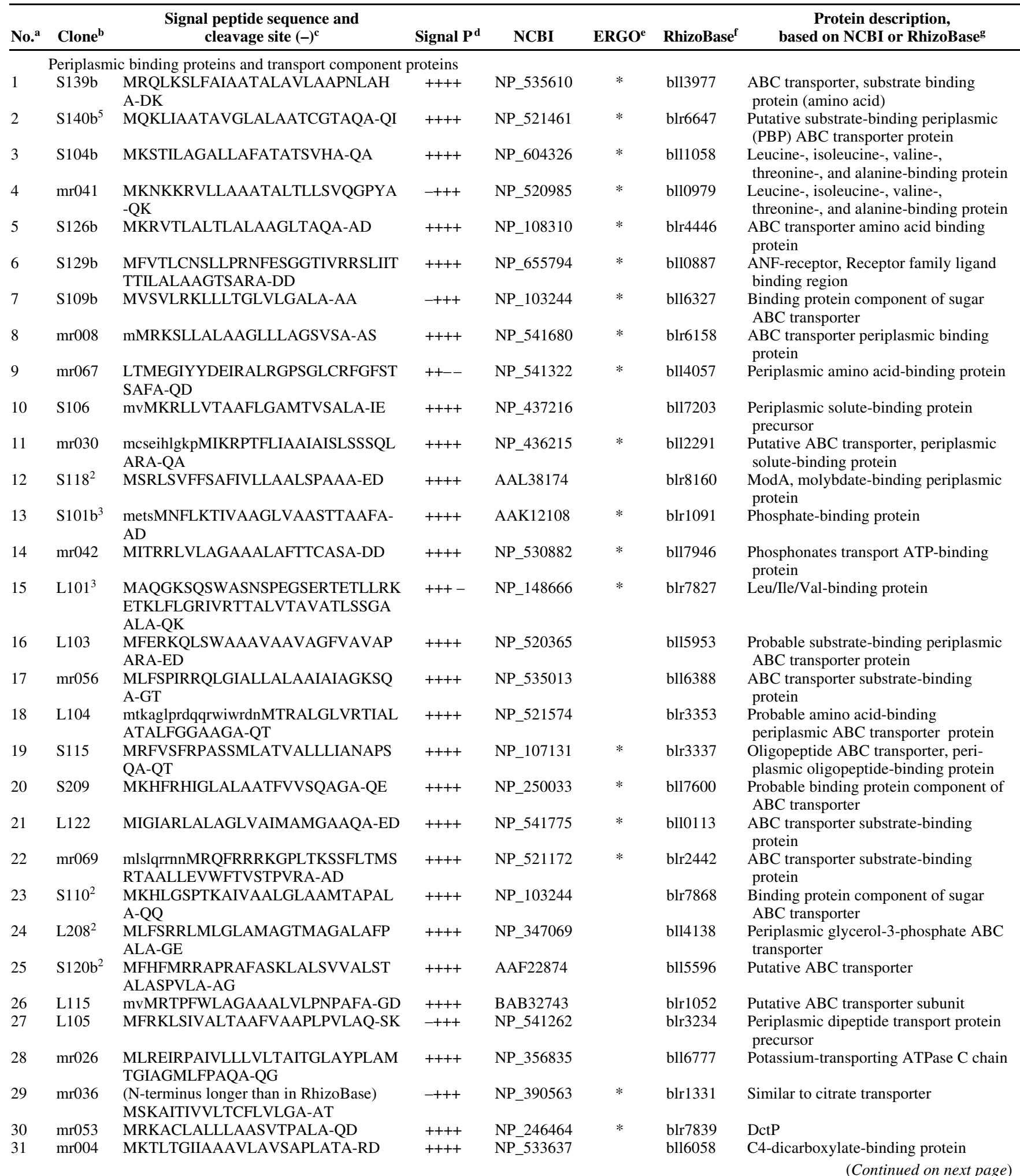

a The numbers are provided in brackets ([ ]) in text to facilitate the identification of individual clones.

b Superscript numbers indicate the number of different clones in which the identical gene is fused to the E-tag.

c The deduced signal peptide sequences are presented in the one-letter code. Lower case letters indicate translational start sites predicted by RhizoBase and upper case letters indicate alternative start sites that are based on our sequence analysis. "-" indicate signal peptidase cleavage sites predicted by Signal P.

$\mathrm{d}$ The result of the signal peptide analysis was compiled as calculated by the SignalP V1.1 WWW prediction server. Four different calculations are presented, "+" means over the cut-off value, and "-" means below the cut-off value.

e Matches to the ERGO database are indicated by asterisks.

$\mathrm{f} \mathrm{N}$-terminal extensions of signal peptides are indicated by " $<$ ".

g The amino acid sequences of transmembrane segments (TMS) are presented between two " ”.

${ }^{\mathrm{h}} \mathrm{nhf}=$ no hit found. 
Table 1. (continued from preceding page)

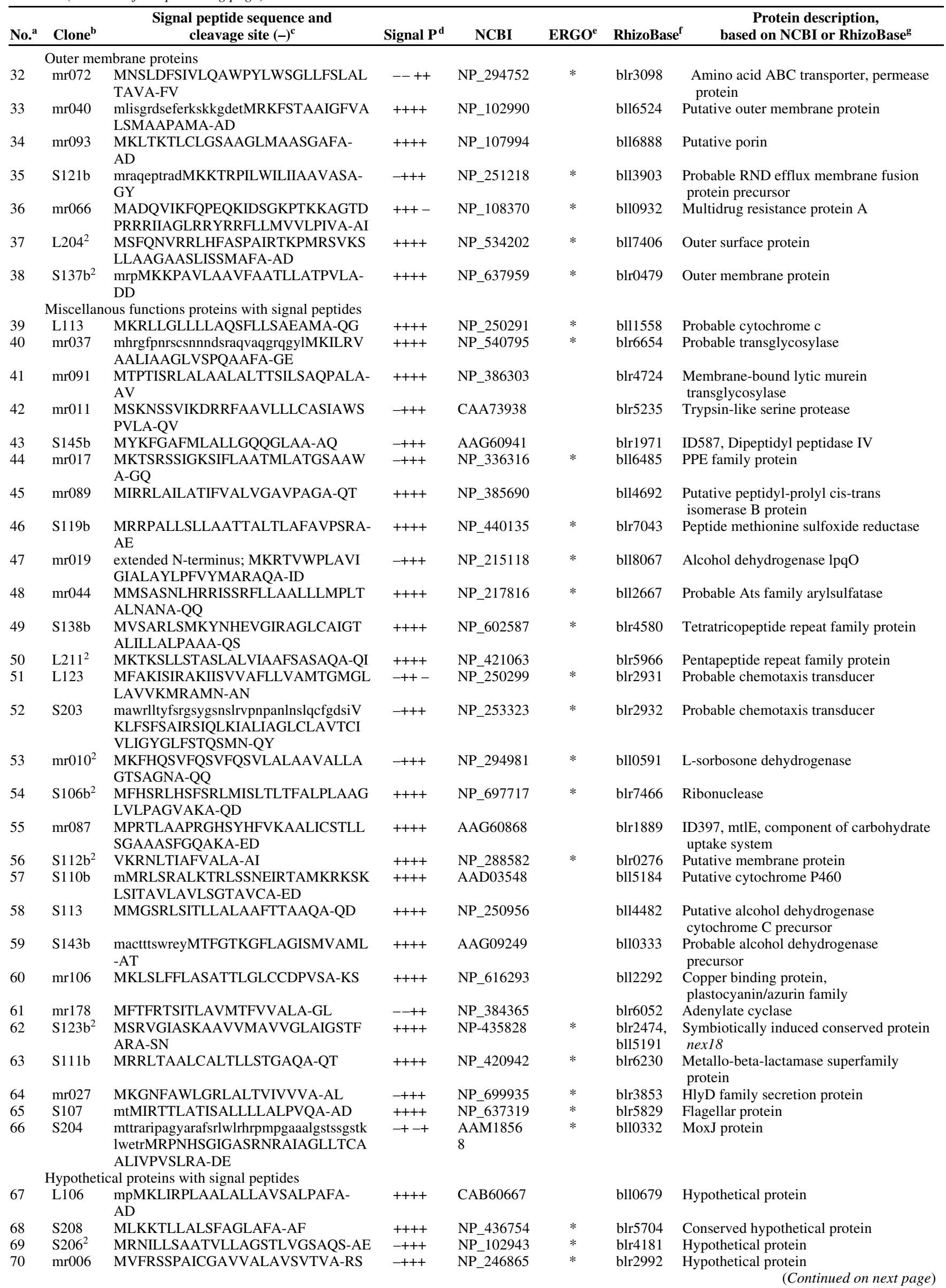


clones after the first panning are higher with this library. This difference may have several explanations. One obvious reason is the sizes of the two libraries; the $S$. aureus library contained approximately $8 \times 10^{5}$ clones, whereas the $B$. japonicum library contained approximately $1 \times 10^{8}$ clones. In a library, only a fraction of the clones will generate phages that display a foreign polypeptide at the surface, since an insert has to have the correct orientation, the ORF in frame with the vector se- quences, and to lack the $3^{\prime}$ stop codon terminating the gene. Still, both libraries should be large enough to display most proteins from the two bacteria. In a large library, the same signal peptide sequence will be present in several different clones, resulting in a greater variation in the length of the polypeptide fused to protein III, which should increase the possibility of display at the phage surface. The DNA fragments used to make the $S$. aureus library were also larger, which may affect the

Table 1. (continued from preceding page)

\begin{tabular}{|c|c|c|c|c|c|c|c|}
\hline No. ${ }^{\mathrm{a}}$ & Clone $^{\mathrm{b}}$ & $\begin{array}{l}\text { Signal peptide sequence and } \\
\text { cleavage site }(-)^{c}\end{array}$ & Signal $P^{d}$ & NCBI & ERGO $^{\mathrm{e}}$ & RhizoBase $^{f}$ & $\begin{array}{l}\text { Protein description, } \\
\text { based on NCBI or RhizoBase }\end{array}$ \\
\hline 71 & $\mathrm{mr} 014^{2}$ & $\begin{array}{l}\text { magprsrpcrltvrrdlMRRSRVLLSAGLTVL } \\
\text { STGLSAGLASA-QN }\end{array}$ & ++++ & NP_010900 & $*$ & blr5306 & Hypothetical protein \\
\hline 72 & $\mathrm{~S} 116^{2}$ & $\begin{array}{l}\text { mrrgacryplrqnnnaalaprrtpMPRPTRCVAS } \\
\text { KTPRAAIATTLAFLALISGVRA-GM }\end{array}$ & -+++ & NP_404758 & & blr0368 & Conserved hypothetical protein \\
\hline 73 & L118 & MDKRLFLATTAAVAIATSALA-QS & ++++ & NP_437450 & $*$ & bll7642 & $\begin{array}{l}\text { Hypothetical exported glutamine-rich } \\
\text { protein }\end{array}$ \\
\hline 74 & mr068 & $\begin{array}{l}\text { meipMKTMLSILFAAGSAVVGCPAHA- } \\
\text { VK }\end{array}$ & ++++ & NP_290089 & * & bl15766 & Hypothetical protein \\
\hline 75 & L102 & $\begin{array}{l}\text { MRKIYLVPALVGLLTFVAAGPVAA- } \\
\text { QG }\end{array}$ & ++++ & NP_293844 & * & blr3251 & Hypothetical protein \\
\hline 76 & S119 & $\begin{array}{l}\text { MRQMISGLVAAAAVMFVGAAPAAA- } \\
\text { CG }\end{array}$ & -+++ & NP_384364 & * & bl15500 & Conserved hypothetical protein \\
\hline 77 & mr046 & MKRAIMILATAALASTLAIGA-AD & -+++ & AAF50813 & * & blr0306 & Hypothetical glycine rich protein \\
\hline 78 & $\operatorname{mr} 105^{2}$ & MLRTVTLSCLALLSAALPVRA-ED & ++++ & NP_355938 & & bl12251 & Conserved hypothetical protein \\
\hline 79 & S114 & $\begin{array}{l}\text { mrnvkafevnwkrrrevnMRLIAIAIAAVTA } \\
\text { MLAGPASA-QQ }\end{array}$ & ++++ & NP_436304 & $*$ & blr1237 & Hypothetical protein \\
\hline 80 & mr095 & $\begin{array}{l}\text { MRDCLNHRAGFDRVLMTVAATFLTV } \\
\text { SASSALA-QD }\end{array}$ & ++++ & NP_102313 & & blr7131 & Hypothetical protein \\
\hline 81 & L210 & MRLRSILVĀALLLAPTAALA-AP & ++++ & NP_534004 & $*$ & blr4223 & Conserved hypothetical protein \\
\hline 82 & $\mathrm{~S} 122 \mathrm{~b}$ & $\begin{array}{l}\text { MKRPQLRRNGTVIKMSNLRFPRTHLQ } \\
\text { GTDMMHLFRTSLGVMALAAAACGP } \\
\text { GGGALA-AN }\end{array}$ & -++- & NP_385600 & $*$ & bll5131 & $\begin{array}{l}\text { Conserved hypothetical transmembrane } \\
\text { protein }\end{array}$ \\
\hline 83 & mr007 & $\begin{array}{l}\text { MRRSGDHLFRRCEMRKLLATAAFLL } \\
\text { ASTAAQA-QY }\end{array}$ & ++++ & NP_334701 & * & blr4562 & Hypothetical protein \\
\hline 84 & S131b & $\begin{array}{l}\text { (actual sequence of E-tag clone S131b); } \\
\text { (MTLQIHT)LVMLAGTAGAVV } \\
\text { (amino acid sequence of corresponding } \\
\text { ORF bll3736); } \\
\text { MIRFLLVLVMLAGTAGA-VV }\end{array}$ & -++ & NP_385993 & $*$ & bl13736 & $\begin{array}{l}\text { Hypothetical transmembrane signal } \\
\text { peptide protein }\end{array}$ \\
\hline 85 & $\mathrm{~S} 147 \mathrm{~b}$ & $\begin{array}{l}\text { msmaaqiaprlntpcpafrngkhflirlrenkhlttvrea } \\
\text { vMTLLIHLKIRTKLASMVCLAALTVT } \\
\text { A-LI }\end{array}$ & -+++ & CAC84419 & & bl14326 & Hypothetical protein \\
\hline 86 & S144b & $\begin{array}{l}\text { MIRHLMVPITAAMITMGAVGAYAQS } \\
\text { AFPAPLPNQA-AS }\end{array}$ & -+++ & $\begin{array}{l}\text { ZP_000107 } \\
36\end{array}$ & & bl17522 & Hypothetical protein \\
\hline 87 & $\mathrm{~S} 202^{2}$ & $\begin{array}{l}\text { MTNLRFVLLATTALTAMQLANTASH } \\
\text { A-QG }\end{array}$ & -+++ & $\begin{array}{l}\text { ZP_000098 } \\
17\end{array}$ & & blr0521 & $\begin{array}{l}\text { Hypothetical protein, extremely proline- } \\
\text { rich }\end{array}$ \\
\hline 88 & mr086 & $\begin{array}{l}\text { MRAPSGILPRFFLALLACWLCLGPAS } \\
\text { A-ET }\end{array}$ & ++++ & NP_104559 & & blr5633 & Hypothetical protein \\
\hline 89 & $\mathrm{mr} 043^{2}$ & $\begin{array}{l}\text { mtigsalspgfkqlrelvrrgcaMMSISGFAYRI } \\
\text { GAVSDPRGMSAKAARRALRTAAVPL } \\
\text { IAAAIALGASPAIA-QD }\end{array}$ & ++++ & NP_356352 & $*$ & blr7677 & Hypothetical protein \\
\hline 90 & L117 & $\begin{array}{l}\text { msppwptsdtapgrittirhdarasavtapsppahsffq } \\
\text { gilVSHKLASALLAALFLAISSLSGA- } \\
\text { QA }\end{array}$ & -++ & $\begin{array}{l}\text { ZP_000346 } \\
83\end{array}$ & & bll6471 & Hypothetical protein \\
\hline 91 & S109 & MKIRFLFLLPLLVSLVPTA-PS & --++ & $\begin{array}{l}\text { ZP_000094 } \\
47\end{array}$ & & blr0352 & Hypothetical protein \\
\hline 92 & $\mathrm{~S} 132 \mathrm{~b}$ & MRRPSLYICISLFTAAAALA-AT & +-++ & NP_436626 & & blr3761 & Hypothetical protein \\
\hline 93 & $\mathrm{mr} 070$ & $\begin{array}{l}\text { MNRRGPVGHMIEAPHRRALFFEDFSD } \\
\text { CILPPRAMVALAVMLAATPALA-AS }\end{array}$ & +++- & $\begin{array}{l}\text { ZP_000093 } \\
58\end{array}$ & & bl13360 & Hypothetical protein \\
\hline 94 & $\mathrm{~S} 125 \mathrm{~b}^{4}$ & $\begin{array}{l}\text { MPALLRPALTALGVACLLSAASLASS } \\
\text { GTAFA-QA }\end{array}$ & ++++ & NP_078918 & * & blr1408 & Hypothetical protein \\
\hline 95 & $\begin{array}{l}\text { Signal p } \\
\text { S103 }\end{array}$ & $\begin{array}{l}\text { tide proteins without homologues in the NCI } \\
\text { MKISRRSPGRARLHGERRPSRFSRRSV } \\
\text { TRGPLMHLSRLICSAFLLVVLPAAYSP } \\
\text { AGAGA-AI }\end{array}$ & $\begin{array}{l}\text { 3I data base } \\
-+++\end{array}$ & & & bl15279 & Unknown protein \\
\hline 96 & $\mathrm{~S} 121^{2}$ & $\begin{array}{l}\text { MVSCPMRPIDRLFSCLALFLAIAAVPV } \\
\text { APVRA-AE }\end{array}$ & ++++ & & & bl17996 & Unknown protein \\
\hline 97 & $\mathrm{~S} 205^{3}$ & $\begin{array}{l}\text { (extended N-terminus) } \\
<\text { MLKTISAALLAASVIAAPAFA-AE }^{\mathrm{f}}\end{array}$ & ++++ & & * & bll5511 & Unknown protein \\
\hline $\begin{array}{l}98 \\
99\end{array}$ & $\begin{array}{l}\mathrm{S}_{108 b^{2}} \\
\mathrm{mr} 098\end{array}$ & $\begin{array}{l}\text { MKFRRLLALAGVFFGMSTVALA-QT } \\
\text { MRERLIPSRTGKFGFQMIAAIVGGLLA }\end{array}$ & $\begin{array}{l}++++ \\
-++-\end{array}$ & & & $\begin{array}{l}\text { blr6329 } \\
\text { bll1555 }\end{array}$ & $\begin{array}{l}\text { Unknown protein } \\
\text { Unknown protein }\end{array}$ \\
\hline
\end{tabular}


efficiency by which the fusion protein is displayed at the phage surface. Furthermore, the genome of $B$. japonicum is much larger than that of $S$. aureus and, thus, should encode many more extracytoplasmic proteins. In addition, B. japonicum is a gramnegative bacterium, like the $E$. coli host used in this system, while $S$. aureus is gram positive, which may affect the export of extracytoplasmic proteins.

When the sequences obtained in this study were blasted against the ERGO database, highly similar sequences were found in the closely related strain B. japonicum USDA 438, even when the sequences were extremely short. However, due to transient availability of the database, not all clones were tested. While this paper was being revised, the complete genome sequence of $B$. japonicum USDA110 was released (Kaneko et al 2002), and thus, all sequences were reblasted. In most cases, the sequence data obtained from the E-tag fusion clones are identical to the USDA 110 genomic sequence. However, in some identified clones in Table 1, translation start sites different from those in RhizoBase were proposed. Furthermore, twelve of the proposed signal pep-

Table 1. (Continued from preceding page)

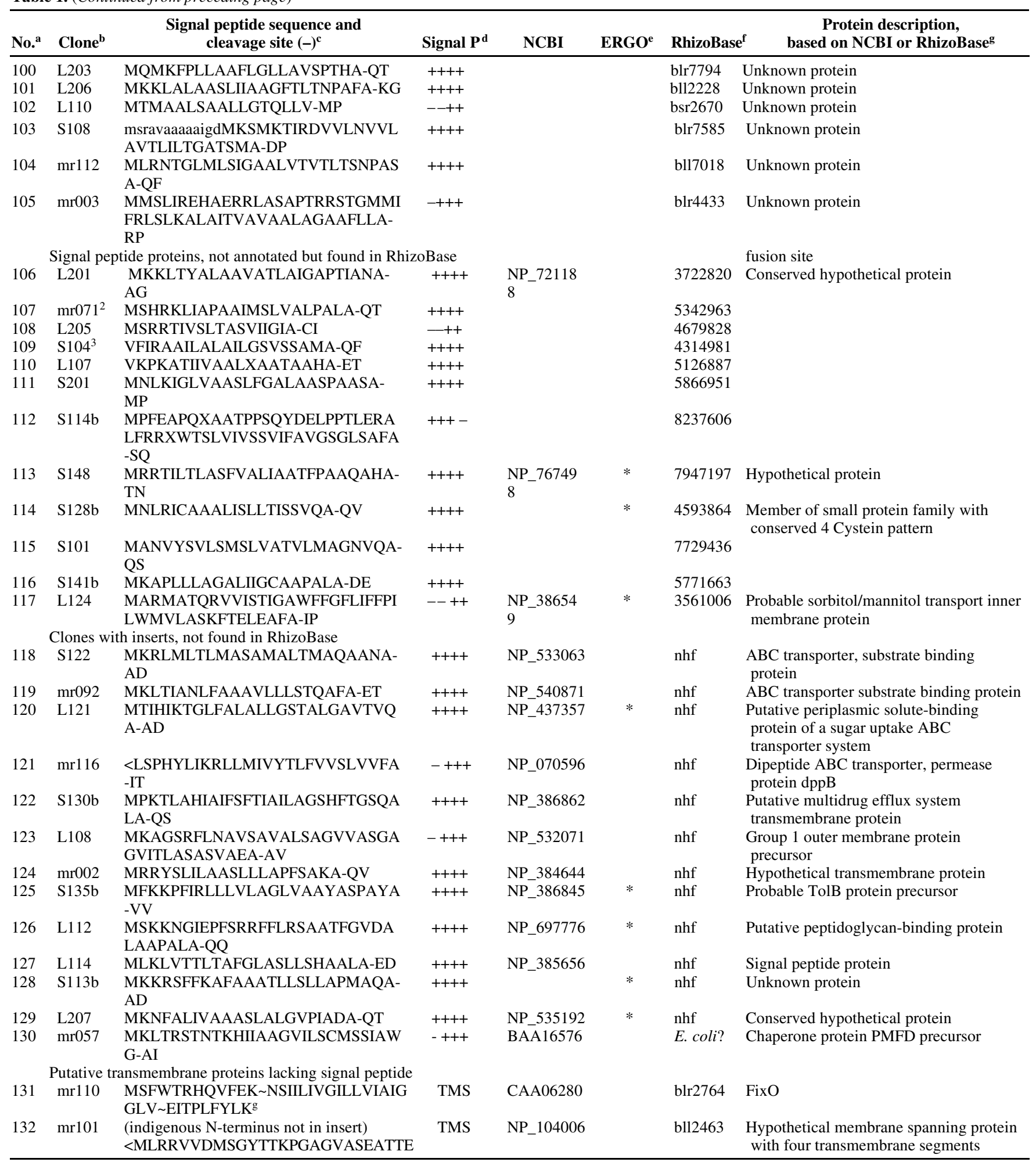


tides in Table 1 correspond to ORFs that have not been annotated in RhizoBase. These newly identified ORFs were either rather small ones or were superimposed with existing ORFs in different reading frames. Surprisingly, the sequences of thirteen E-tag fusion clones could not be identified within the complete genomic sequence. This could have several explanations. The most obvious one would be that the library is contaminated with $E$. coli DNA derived from preparation of the phagemid DNA. However, only one of these clones contains a sequence found in the E. coli genome (mr057 [130]), while several other sequences are more homologous to DNA from other rhizobial species. Furthermore, several of these sequences were identified in the ERGO database. Hence, it seems likely that the inserts in these clones are derived from Bradyrhizobium and represent genes not present in all strains.

The function and subcellular localization of several of the proteins identified in this study has been known earlier and supports an extracytoplasmatic localization. For example, clones mr087 ([55] ID397) and S145b ([43] ID587) were found to be located within the $410-\mathrm{kb}$ symbiotic region and have been predicted to have N-terminal signal peptides (Göttfert et al. 2001). ID397 has been designated $m t l E$; the protein encoded by this gene is a component of sugar metabolism. In Escherichia coli and in Pseudomonas fluorescens, MtlE has been demonstrated to be a periplasmic subunit of the periplasmic maltose binding protein (Brunker et al. 1998). Interestingly, a protein encoded by two different clones (S123b and mr081 [62]), had earlier been found by Dainese-Hatt and associates (1999) in an experiment in which differential expression of periplasmatic proteins in B. japonicum were studied under anaerobic and aerobic conditions. The N-terminal sequence of this protein (SNQDIVDTAVGAGQ) was in perfect agreement with the predicted processing site of clones $\mathrm{S} 123 \mathrm{~b}$ and $\mathrm{mr} 081$ [62]. In the completed $B$. japonicum genome, there are two identical copies of this gene (blr2474 and bll5191 that exhibit significant similarity to a nodule-expressed gene in Sinorhizobium meliloti (nex18) (Oke and Long 1999).

The combination of the genome sequence data with large scale, high-throughput functional genomic methods is needed to assign a biological role to each gene. According to Greenbaum and associates (2001), a key approach in genomic research is to divide the cellular contents into distinct subpopulations, e.g., transcriptome, translatome, etc., and study these subsets with available experimental methods, e.g., DNA microarray analysis, 2D gel electrophoresis, and other techniques. Although valuable data can be withdrawn from the raw nucleotide sequence data by various computa-

Table 2. Analysis of selected clones to verify the judgement of translocation positive and negative clones

\begin{tabular}{lccc}
\hline Clone & $\begin{array}{c}\text { Extra- } \\
\text { cellular }^{\mathbf{a}}\end{array}$ & Recovery $(\mathbf{c f u} / \mathbf{2 0 0} \boldsymbol{\mu l})$ & $\begin{array}{c}\text { Functional }^{\text {sugnal peptide }} \\
\text { sign }\end{array}$ \\
\hline S105 & Yes & $1.4 \times 10^{4}$ & Yes \\
S148 & Yes & $4.6 \times 10^{5}$ & Yes \\
S109 & Yes & $3.7 \times 10^{5}$ & Yes \\
L205 & Yes & $4.3 \times 10^{4}$ & Yes \\
S202 & Yes & $1.1 \times 10^{5}$ & Yes \\
S104 & Yes & $2.9 \times 10^{5}$ & Yes \\
S130b & Yes & $1.1 \times 10^{5}$ & Yes \\
S120 & No & $<4$ & No \\
S103b & No & $<4$ & No \\
S115b & No & $<4$ & No \\
S124b & No & $<4$ & No \\
S131b & No & $1.5 \times 10^{3}$ & $?$ \\
\hline
\end{tabular}

${ }^{a}$ As determined from the deduced amino acid sequence.

${ }^{\mathrm{b}}$ As determined after selection of phage stock against anti E-tag antibodies. tional analyses, these predictions need experimental verifications. When the secretome of Bacillus subtilis was identified by mass spectrometry, it turned out that only $50 \%$ of the extracellular proteome was included in genome-based predictions (Antelmann et al. 2001). Secreted proteins (secretome) are of special interest in the symbiotic context. Rhizobia are known to secrete several proteins into the surrounding environment, some of which have a role in interactions with the plant (Fahraeus and Ljunggren 1959; Hubbell et al. 1978; Ljunggren and Fahraeus 1961). The availability of complete genome sequence data and efficient large scale functional genomic methods such as the display system used in this paper will be a powerful tool to investigate complex events in any microorganism. Especially when such an approach is combined with microarray techniques, phagemid-DNA probes hybridizing to a genome chip would instantly indicate genes for all extracytoplasmic proteins available in the library. With reference to the low rate of identical or overlapping clones and the high number of phages in the eluate from the repanning, it is likely that a large part of the "secretome" of B. japonicum is present in just a microliter of the phage eluate.

A number of clones encode proteins and could be interesting to examine further because of special features revealed in the amino acid composition. The perhaps most interesting protein is encoded by clone S148 [113], which contains a conserved core region with four cystein residues. When the core region of S148 was blasted against all available genomes in the NCBI database, a protein family of 17 members could be identified, denoted the $4 \mathrm{C}$-family. Eleven of these members were found in B. japonicum and six in $R$. palustris, all containing a putative signal peptide. In addition to the cysteins, the protein family also contains other conserved motifs (Fig. 2), and all are very small proteins in the range of 43 to 71 amino acids, after removal of the N-terminal signal peptide. The small protein size and the signal peptide suggest that they are exported out of the bacteria. Disulfide bridges between cysteins increase the stability of proteins and are often found in small proteins with important functions, such as chemokines, which usually also contain four cysteins and are of a size similar to the family identified here. The functional meaning of these small proteins of the 4C-family in $B$. japonicum and $R$. palustris, which are taxonomically closely related members of the $\alpha$ proteobacteria, remains to be elucidated.

Our future efforts will concentrate on studying the functional relevance of some of these identified genes and their gene products in free-living $B$. japonicum cells and in their symbiotic interaction with soybean. Furthermore, this collection of clones encoding secreted E-tag fusion proteins gives the opportunity to prove experimentally whether some precursor proteins have to be processed exclusively by one of the three signal peptidases present in B. japonicum and whether the signal peptidases are specific for certain types of patterns in signal peptides.

\section{MATERIALS AND METHODS}

Bacterial strains, helper phage, and enzymes.

E. coli TG1 (Sambrook et al. 2001) was used for construction of the library and production of phage stocks. The library was constructed using chromosomal DNA from B. japonicum USDA110spc4 (Regensburger and Hennecke 1983). Phage R408 (Promega, Madison, WI, U.S.A. ) was used as helper phage. E. coli transformants were grown in Luria-Bertani broth (LB) or on agar (LA) supplied with 50 to $100 \mu \mathrm{g}$ of ampicillin (Amp) per $\mathrm{ml}$. Restriction and modifying enzymes were from 
MBI Fermentas AB (Vilnius, Lithuania), except for calf intestine alkaline phosphatase that was from Amersham Pharmacia Biotech (Uppsala, Sweden).

\section{Construction of the $B$. japonicum library.}

The library was constructed essentially as described by Jacobsson and Frykberg (1995). In short, B. japonicum genomic DNA was fragmented by sonication and was made blunt-ended by $\mathrm{T} 4$ polymerase treatment. The genomic fragments, ranging in size between 0.5 to $2 \mathrm{~kb}$, were ligated to SnaBI-cleaved and calf intestinal phosphatase-treated pG3DSS vector (Rosander et al. 2002) in five Ready-To-Go T4 DNA ligase tubes (Amersham Pharmacia Biotech). The ligated material was electrotransformed into E. coli TG1, and a 4-ml aliquot of the overnight culture was infected with helper phage (moi 50), was mixed with $0.5 \%$ soft agar, and was poured onto LA/Amp plates. After incubation overnight, the phages were extracted from the soft agar by transferring the soft agar to 1 vol $\mathrm{LB}$ and shaking the mixture for $4 \mathrm{~h}$ at $37^{\circ} \mathrm{C}$. Thereafter, the soft agar was removed by centrifugation at $16,000 \mathrm{rpm}$ for 10 min, and the supernatant was filtered through a $0.45-\mu \mathrm{m}$ sterile filter. This procedure usually gives a phagemid titer of $10^{10}$ to $10^{11} \mathrm{CFU} / \mathrm{ml}$.

\section{Panning procedures.}

Phages displaying fusion protein were isolated by panning against $\alpha$-E-tag antibodies. Microwell plates (MaxiSorp Nunc, Copenhagen, Denmark) were coated with $200 \mu \mathrm{l}$ of monoclonal $\alpha$-E-tag antibodies (Amersham Pharmacia Biotech) at a final concentration of $15 \mu \mathrm{g} / \mathrm{ml}$ in $0.05 \mathrm{M}$ sodium-carbonate, $\mathrm{pH}$ 9.7. After blocking with $400 \mu \mathrm{l}$ of $100 \mu \mathrm{g}$ of casein per ml in phosphate-buffered saline with $0.05 \%$ Tween20 (PBS-T), $200 \mu \mathrm{l}$ of the phage library was added to the wells and was incubated at room temperature on a shaker for $4 \mathrm{~h}$. The wells were rinsed 30 times with PBS-T, and bound phages were eluted with $200 \mu \mathrm{l} 50 \mathrm{mM}$ Na-citrate and $140 \mathrm{mM} \mathrm{NaCl}, \mathrm{pH} 2.0$, followed by neutralization with $50 \mu \mathrm{l} 2 \mathrm{M}$ Tris- $\mathrm{HCl}, \mathrm{pH}$ 8.0. The eluate was used for infection of $E$. coli TG1 cells (overnight culture), which were plated on LA supplied with ampicillin. The clones obtained were resuspended in LB and were infected with helper phage for production of a phage stock for repanning. The second enrichment cycle (repanning) was made according to the same protocol but with a 2-h-long panning.

\section{DNA sequencing and sequence analysis.}

After panning against the $\alpha$-E-tag antibodies, clones were picked at random, and the sequence of the inserted DNA frag- ments was determined. Sequencing was carried out using primer G3DelRev (5'-CCAGCATTGACAGGAGGTTGAGGC-3') or primer G3DSSfw (5'-CTTTTACTTCCTGAATAAATCTTTCAG-3') (Invitrogen AB, Stockholm, Sweden, or MWG-Biotech, Eberswald, Germany) and the DYEnamic ET terminator cycle sequencing premix kit (Amersham Pharmacia Biotech) and was analyzed on ABI PRISM 377 DNA Sequencer (PerkinElmer Instruments). Alternatively, the DYEnamicTM Direct cycle sequencing kit (Amersham Life Science, Inc. Cleveland, Ohio, U.S.A.) was used in combination with IRD-labeled primers, and separation of samples was carried out with a LI-COR sequencing machine, model 4000. DNA sequences obtained were analyzed by the Vector NTI 5 software (InforMax Inc., Bethesda, MD, U.S.A.) and were evaluated for predicted extracellularity by the Signal P V1.1 algorithm with gram-negative data (Nielsen et al. 1997) and the TMHMM V2.0 Transmembrane Prediction server (Cserzo et al. 1997). All inserts were sequenced from the $3^{\prime}$ end, since our interest was focused on ORFs in fusion with the E-tag $\Delta$ gene III. However, some clones were also sequenced from the $5^{\prime}$ end, using the primer G3DSSfw, and clones for which the gene start was still lacking were sequenced, using two internal primers for each clone. These clones are: L101, L103, L114, S107B, S112B, S114, S115, S121B, S122B, and S209. The primers used have the following sequences: prL101: CTTGGAAGAATAGTGCGAACCA, prL101i: GGCTCGGATACCTCGTAGCTCT, prL103: TACCGGGTTGGAGCCGGCGCGA, prL103i: TCTCGATCTGCTTGCCGGTCGA; prL114: CGACCAGATCCTGTTGCGCTTC, prL114i: GTCGATCGTCGGTAGAGCCGGT, prS107B: GGCACCGCCTTCGTGGTGCTGC, prS107Bi: CGCCGCCGTTCTTGTTGACCCA, prS112B: CGCCGGAATCAAGTCCGTCCGT, prS112Bi: GTATAGCTGAGCTGGACGTTGG, prS114: GGGCCGCATCGGCCCAGCAAT, prS114i: CATCGTCAGCTTACCGGGCTCG, prS115: CAACTTGCTTGTTTCTTAACCT, prS115i: CGTGCTCCTTGGCGAACTTCGA, prS121B: GAGCTTCTGGTCTCGATCGATC, prS121Bi: GGCTCGACCTGCGAGATCGTGA, prS122B: CTCCGCTCCAAACTCCTGGGA, prS122Bi: CGGCGTCCTCCCAGGAGTTGGA, prS209: AGCATTTCCGTCACATCGGGCT, prS209i: CCGGTGTCCTTGATGTTCTTCA. The following IRD800-labeled primers were used for internal sequencing reactions: MR030F CCTACGTTCCTTATTGCGGCGATCG, MR066F GTCTATGCCGACAAGGAGGCGTCG, MR066R CTTGCGCTCGACGTCGCGCTGCTTG, MR115 CCGGCTTCCGGTCGGTGCCGAAG, and MR112SP CAGATCTGATGCTGTCCATCGGTG. Homology searches were performed using the BLAST database (Altschul
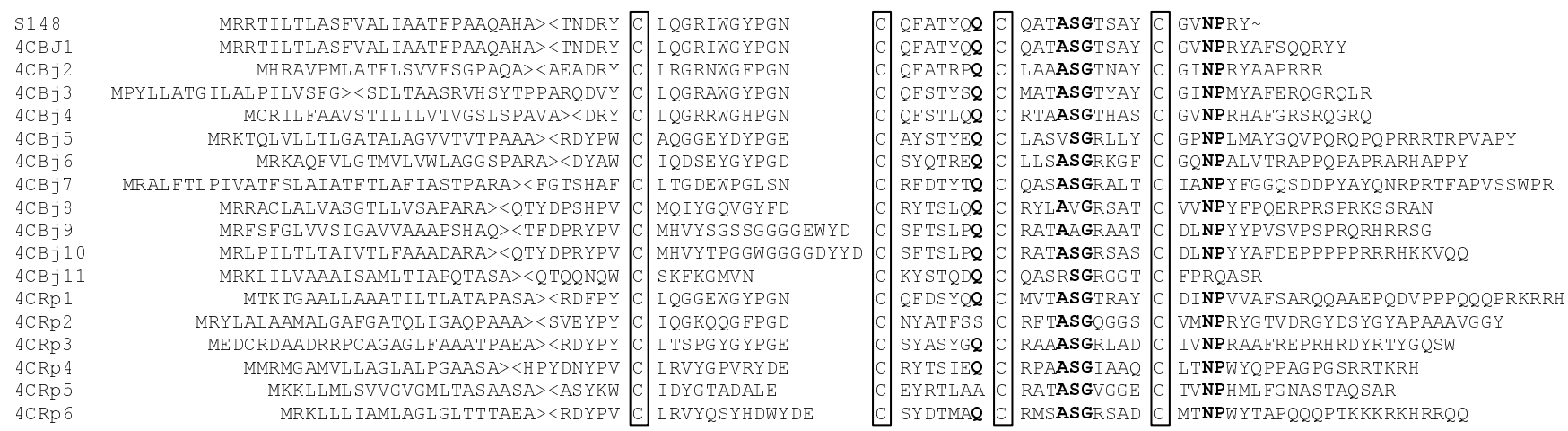

Fig. 2. Protein sequence alignment of the 4C-protein family. At the top the deduced amino acid sequence of clone S148 [113] (derived from strain USDA110spc4) is shown in the one-letter code. The E-tag fusion site is indicated by a wavy line ( ). Highly conserved positions are printed in bold and cysteine residues are boxed. Putative signal peptide cleavage sites are represented by two arrow heads $(><)$. All proteins constitute a novel family of $4 \mathrm{C}$ proteins. Those with designations $4 \mathrm{CBj} 1-11$ are obtained from the genomic sequence of strain USDA110, those with designations 4CRp1-6 are obtained from the genomic sequence of Rhodopseudomonas palustris. 
et al. 1990) at the National Center for Biotechnology Information. A BLAST search was also performed using the partial B. japonicum genome of strain USDA438 sequence data available on the ERGO site of Integrated Genomics. Finally, when the total B. japonicum genome was available on Kazusa Institute's RhizoBase, our sequencing data were used to identify the corresponding ORFs in this database.

\section{Display of the E-tag on phage \\ from positive and negative clones.}

After sequence analysis, all clones were classified as either positive or negative with regard to being extracytoplasmic. Phage stocks from twelve clones were prepared by infection with helper phage and extraction from soft agar, as described above, in order to test the efficiency by which the fusion protein is displayed at the phage surface. The titer of the phage stocks was adjusted to $1 \times 10^{8} \mathrm{CFU} / \mathrm{ml}$ and was panned against $\alpha$-E-tag antibodies, according to the protocol described above.

\section{ACKNOWLEDGMENTS}

We gratefully acknowledge the generous offer by Integrated Genomics to use the ERGO database. In particular, we owe many thanks to R. Overbeck and his colleagues. H. Thierfelder, Philipps University Marburg, contributed in preparing genomic DNA of B. japonicum. We would also like to thank K. Jacobsson and M. Lindberg for critically reading the manuscript. Many thanks to H.-M. Fischer and H. Hennecke (ETH Zurich, Switzerland) for their helpful discussions. This study was supported by Carl Trygger Foundation grant CTS01:146 and a DFG grant to the SFB 395. P. Müller dedicates this paper to D. Werner on the occasion of his 65 th birthday.

\section{LITERATURE CITED}

Altschul, S. F., Gish, W., Miller, W., Myers, E. W., and Lipman, D. J. 1990. Basic local alignment search tool. J. Mol. Biol. 215:403-410.

Antelmann, H., Tjalsma, H., Voigt, B., Ohlmeier, S., Bron, S., van Dijl, J. M., and Hecker, M. 2001. A proteomic view on genome-based signal peptide predictions. Genome Res. 11:1484-1502.

Bairl, A., and Müller, P. 1998. A second gene for Type I signal peptidase in Bradyrhizobium japonicum, sipF, is located near genes involved in RNA processing and cell division. Mol. Gen. Genet. 260:346-356.

Berks, B. C. 1996. A common export pathway for proteins binding complex redox cofactors? Mol. Microbiol. 22:393-404.

Broome-Smith, J. K., Tadayyon, M., and Zhang, Y. 1990. $\beta$-lactamase as a probe of membrane protein assembly and protein export. Mol. Microbiol. 4:1637-1644.

Brunker, P., Altenbuchner, J., and Mattes, R. 1998. Structure and function of the genes involved in mannitol, arabitol and glucitol utilization from Pseudomonas fluorescens DSM50106. Gene 206:117-126.

Cserzo, M., Wallin, E., Simon, I., von Heijne, G., and Elofsson, A. 1997. Prediction of transmembrane $\alpha$-helices in prokaryotic membrane proteins: The dense alignment surface method. Protein Eng. 10:673-676.

Dainese-Hatt, P., Fischer, H.-M., Hennecke, H., James, P. 1999. Classifying symbiotic proteins from Bradyrhizobium japonicum into functional groups by proteome analysis of altered gene expression levels. Electrophoresis 20:3514-3520.

Danese, P. N., and Silhavy, T. J. 1998. Targeting and assembly of periplasmic and outer-membrane proteins in Escherichia coli. Annu. Rev. Genet. 32:59-94.

Fahraeus, G., and Ljunggren H. 1959. The possible significance of pectic enzymes in root hair infection by nodule bacteria. Physiol. Plant. $12: 145-154$.

Galibert, F., Finan, T. M., Long, S. R., Pühler, A., Abola, P., Ampe, F., Barloy-Hubler, F., Barnett, M. J., Becker, A., Boistard, P., Bothe, G., Boutry, M., Bowser, L., Buhrmester, J., Cadieu, E., Capela, D., Chain, P., Cowie, A., Davis, R. W., Dreano, S., Federspiel, N. A., Fisher, R .F., Gloux, S., Godrie, T., Goffeau, A., Golding, B., Gouzy, J., Gurjal, M., Hernandez-Lucas, I., Hong, A., Huizar, L., Hyman, R. W., Jones, T., Kahn, D., Kahn, M. L., Kalman, S., Keating, D. H., Kiss, E., Komp, C., Lelaure, V., Masuy, D., Palm, C., Peck, M. C., Pohl, T. M., Portetelle, D., Purnelle, B., Ramsperger, U., Surzycki, R., Thebault, P., Vandenbol, M., Vorholter, F. J., Weidner, S., Wells,
D. H., Wong, K., Yeh, K. C., and Batut, J. 2001. The composite genome of the legume symbiont Sinorhizobium meliloti. Science 293:668-672

Greenbaum, D., Luscombe, N. M., Jansen, R., Qian, J., and Gerstein, M. 2001. Interrelating different types of genomic data, from proteome to secretome: Homing in on function. Genome Res. 11:1463-1468.

Göttfert, M., Röthlisberger, S., Kündig, C., Beck, C., Marty, R., and Hennecke, H. 2001. Potential symbiosis-specific genes uncovered by sequencing a 410-kilobase DNA region of the Bradyrhizobium japonicum chromosome. J. Bacteriol. 183:1405-1412.

Hubbell, D. H., Morales, V. M., and Umali-Garcia, M. 1978. The role of polygalacturonase in root-hair invasion by nodule bacteria. J. Gen. Microbiol. 26:521-528.

Jacobsson, K., and Frykberg, L. 1995. Cloning of ligand-binding domains of bacterial receptors by phage display. Biotechniques 18:878885.

Kaneko, T., Nakamura, Y., Sato, S., Minamisawa, K, Uchiumi, T., Sasamoto, S., Watanabe, A., Idesawa, K., Iriguchi, M., Kawashima, K., Kohara, M., Matsumoto, M., Shimpo, S., Tsuruoka, H., Wada, T., Yamada, M., and Tabata, S. 2002. Complete genomic sequence of nitrogen-fixing symbiotic bacterium Bradyrhizobium japonicum USDA110. DNA Res. 9:189-197.

Ljunggren, H., and Fahraeus, G. 1961. The role of polygalacturonase in root-hair invasion by nodule bacteria. J. Gen. Microbiol. 26:521-528.

Lugtenberg, B. J. J. 1998. Outer membrane proteins. Pages 45-53 in: The Rhizobiaceae-Molecular Biology of Model Plant-Associated Bacteria. H. P. Spaink, A. Kondorosi,, and P. J. J. Hooykaas, eds. Kluwer Academic Publishers, Dordrecht, The Netherlands.

Manoil, C., Mekalanos, J. J., and Beckwith, J. 1990. Alkaline phosphatase fusions: Sensors of subcellular location. J. Bacteriol. 172:515-518.

Meyer, D. I., Krause, E., and Dobberstein, B. 1982. Secretory protein translocation across membranes-The role of the "docking protein". Nature 297:647-50.

Müller, P., Ahrens, K., Keller, T., and Klaucke, A. 1995a. A TnphoA insertion within the Bradyrhizobium japonicum sipS gene, homologous to prokaryotic signal peptidases, results in extensive changes in the expression of PBM-specific nodulins of infected soybean (Glycine max) cells. Mol. Microbiol. 18:831-840.

Müller, P., Klaucke, A., and Wegel, E. 1995b. TnphoA-induced symbiotic mutants of Bradyrhizobium japonicum that impair cell and tissue differentiation in Glycine max nodules. Planta 197:163-175.

Nielsen, H., Engelbrecht, J., and Brunak, S. 1997. Identification of prokaryotic and eukaryotic signal peptides and prediction of their cleavage sites. Protein Eng. 10:1-6.

Nielsen H., Brunak, S., and von Heijne, G. 1999. Machine learning approaches for the prediction of signal peptides and other protein sorting signals. Protein Eng 12:3-9.

Oke, V., and Long, S. R. 1999. Bacterial genes induced within the nodule during the Rhizobium-legume symbiosis. Mol. Microbiol. 32:837-849.

Perlman, D., and Halvorson, H. O. 1983. A putative signal peptidase recognition site and sequence in eukaryotic and prokaryotic signal peptides. J. Mol. Biol. 167:391-409.

Pugsley, A. P. 1993. The complete general secretory pathway in gramnegative bacteria. Microbiol. Rev. 57:50-108.

Regensburger, B., and Hennecke, H. 1983. RNA polymerase from Rhizobium japonicum. Arch. Microbiol. 135:103-109.

Rosander, A., Bjerketorp, J. Frykberg, L., and Jacobsson, K. 2002. Phage display as a novel screening method to identify extracellular proteins. J. Microbiol. Meth. 51:43-55.

Russel M., Linderoth, N. A., and Sali A. 1997. Filamentous phage assembly: Variation on a protein export theme. Gene 192:23-32.

Sambrook, J., and Russell, D. W. 2001. Molecular Cloning: A Laboratory Manual, 3rd ed. Cold Spring Harbor Laboratory Press, Cold Spring Harbor, New York.

Samuelson, J. C., Chen, M , Jiang, F., Moller, I., Wiedmann, M., Kuhn, A., Phillips, G. J., and Dalbey, R. E. 2000. YidC mediates membrane protein insertion in bacteria. Nature 406:637-641.

Smith, G., and Petrenko, V. A. 1997. Phage display. Chem. Rev. 97:391410 .

Stuart, R. A., and Neupert, W. 2000. Making membranes in bacteria. Nature 406:575-577.

Tjalsma, H., Bolhuis, A., Jongbloed, J. D., Bron, S., and van Dijl, J. M. 2000. Signal peptide-dependent protein transport in Bacillus subtilis: A genome-based survey of the secretome. Microbiol. Mol. Biol. Rev. 64:515-547.

von Heijne, G. 1983. Patterns of amino acids near signal-sequence cleavage sites. Eur. J. Biochem. 133:17-21.

Wu, H.C. 1996. Biosynthesis of lipoproteins. Pages 1005-1014 in: Escherichia coli and Salmonella: Cellular and Molecular Biology, 2nd 
ed. F. C. Neidhart, R. Curtiss, J. L. Ingraham, E. C. C. Lin, H. B. Low, B. Magasanik, W. S. Reznikoff, M. Riley, M. Schaechter, and H. E. Umbarger, eds. American Society for Microbiology, Washington, D.C.

\section{AUTHOR-RECOMMENDED INTERNET RESOURCES}

INRA Sinorhizobium meliloti strain 1021 Genome Project webpage: sequence.toulouse.inra.fr/meliloti.html
Kazusa Institute RhizoBase webpage: www.kazusa.or.jp/rhizobase/ Bradyrhizobium/

The Center for Biological Sequence signal P prediction server, Technical University of Denmark: www.cbs.dtu.dk/services/SignalP

The Stockholm Bioinformatics Center Transmembrane Prediction server: www.sbc.su.se

The National Center for Biotechnology Information BLAST database: www.ncbi.nlm.nih.gov

Integrated Genomics ERGO database: ergo.integratedgenomics.com/ $\mathrm{ERGO/}$. 